\title{
The Role of Ultrasound in the Diagnosis of Complications Associated with Maternal Diabetes
}

\author{
Kallie Appleton, Jami Barnard, Adam K Jantz, Ritsuko Pooh, Carmina Comas-Gabriel, Sanja Kupesic-Plavsic
}

\begin{abstract}
Gestational diabetes mellitus (GDM) is defined as glucose intolerance that begins or is first recognized during pregnancy. Numerous clinical factors are associated with an increased likelihood of GDM, such as increasing age, obesity, ethnicity, family history of diabetes and past obstetric history. There is a well-documented relationship between maternal hyperglycemia and increased rate of macrosomia, cesarean section, stillbirth, fetal congenital malformations, shoulder dystocia, hypoglycemia, hyperbilirubinemia, pre-eclampsia, preterm delivery, childhood obesity, and increased risk of maternal development of type 2 DM later on in her life. This case-based review is designed to provide health care workers a framework on using various ultrasound imaging modalities in early detection of the effects of gestational diabetes, and the specific conditions and/or anomalies seen in diabetic pregnancies.
\end{abstract}

Keywords: Pregestational diabetes, Gestational diabetes, Type 2 diabetes mellitus, Type 1 diabetes mellitus, Macrosomia, Hypoglycemia, Shoulder dystocia, P reterm delivery, Stillbirth, Pre-eclampsia.

How to cite this article: Appleton K, Barnard J , J antz AK, Pooh $\mathrm{R}$, Comas-Gabriel C, Kupesic-P lavsic S. The Role of Ultrasound in the Diagnosis of Complications Associated with Maternal Diabetes. Donald School J Ultrasound Obstet Gynecol 2013;7(4):506-515.

\section{Source of support: Nil}

Conflict of interest: None declared

\section{INTRODUCTION}

Diabetes is of growing concern in pregnancy, as the physiological consequences of the increasingly obese population carry increased risk for both mother and developing fetus. In 2009 it was estimated that gestational diabetes mellitus (GDM ) affects approximately $7 \%$ of births occurring in the U nited States each year. ${ }^{1}$ Existent data suggests that well over half, approximately $70 \%$, of patients with GDM are of body mass indexes (BMIs) greater than or equal to $25 .{ }^{2}$ It has been established that rates of type 2 diabetes mellitus (DM) are directly correlated with maternal obesity, ${ }^{3}$ and research indicated that the prevalence of GDM in a population is a reflection of the prevalence of type 2 DM in a population. ${ }^{4}$

Pregestational and gestational diabetes have been associated with many adverse pregnancy outcomes for both mother and fetus/neonate to include the following: macrosomia, increased risk of cesarean section, stillbirth, fetal congenital malformations, shoulder dystocia, hypoglycemia, hyperbilirubinemia, pre-eclampsia, preterm delivery, childhood obesity and increased risk of maternal development of type 2 DM later on. ${ }^{5-7}$

Data from literature suggest that actively treating women with pregestational diabetes prior to pregnancy can decrease the rates of congenital malformation and adverse outcomes. ${ }^{8}$ In the same respect, active implementation of treatment for gestational diabetes has been shown to reduce perinatal morbidity and improve outcomes. ${ }^{9}$ This case-based review is designed to provide health care workers a framew ork on using various ultrasound imaging modalities in early detection of the effects gestational diabetes has on pregnancy, and the specific conditions and/or anomalies seen in such cases.

\section{CASE REPORTS}

\section{Case 1}

A 28-year-old G1P0 Hispanic woman presents to your office to establish care, as she has recently discovered that she is pregnant. Her last menstrual period was around 3 months ago. She is unable to remember the exact date, as she has a history of irregular periods. Her menarche was at age 13. The patient's cycles are irregular. The patient is currently sexually active and uses condoms. She has never had an abnormal Pap smear or been diagnosed with an STD. Her medical history is unremarkable. A fter routine blood work ordered by her internist 8 months ago, she was told that she needs to watch what she eats and start exercising, as her sugars were a little high. She currently takes no medications. Her family history is significant for hypertension and type $2 \mathrm{DM}$ in her father and breast cancer in her paternal grandmother. The patient works as an elementary school teacher and lives with her husband. Her social history is unremarkable. She denies smoking, drugs or alcohol. On physical exam, the patient is an overweight female, with B M I of 28. She has a gravid uterus, estimated at 11 weeks' gestation by size. A $n$ ultrasound confirms an intrauterine pregnancy of estimated 11 weeks' gestation (Fig. 1).

\section{Case 2}

A 35-year-old G 2P1001 Latin A merican female at 20 weeks gestation presents to your office for follow-up on a routine prenatal care visit. The patient came to the clinic earlier this week for her routine visit. Y ou noticed that her fundal 

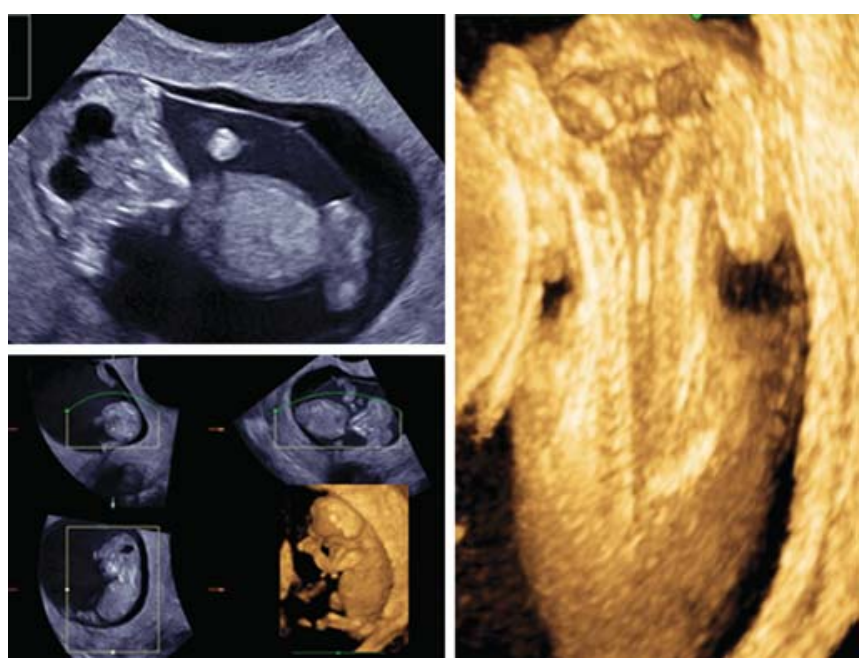

Fig. 1: Transvaginal sonogram and 3D image of the patient presenting at 11 weeks gestation. Courtesy: Pooh R, MD

height was larger than what would be expected for her gestation. Y ou asked her to return later that week for repeat measurements. The patient has significant medical history for pregestational type $2 \mathrm{DM}$ since age 30 . Prior to pregnancy, she controlled her diabetes with diet and exercise. She has had difficulty controlling her blood sugars during pregnancy, and her hemoglobin A $1 \mathrm{C}$ was high. The patient lives with her husband and his son, as well as her daughter from a previous marriage. She does not smoke or drink alcohol. She works as an accountant. On physical examination, the patient is overweight, at a B M I of 29. Her abdomen is gravid, and fundal height measures $41 \mathrm{~cm}$. O n speculum examination, there is a small amount of fluid in the back of the vaginal canal. Y ou send the patient for ultrasound, and the results of amniotic fluid assessment are demonstrated in Figure 2.

\section{Case 3}

A n obese 25-year-old G 1P0 H ispanic female comes to your clinic for establishment of care. She comes from Juarez, $M$ exico, and wishes to establish prenatal care in A merica. She carries her medical records from a clinic in J uarez. Y ou elicit her past medical history, and find that the patient claims she has been healthy for the duration of her life, despite obesity for approximately 10 years. She has never had any operations, and denies any allergies. She does not smoke, drink al cohol or use illicit drugs. She says her last menstrual period was 'weeks' ago. On physical exam, the patient is grossly overweight. Y ou calculate her BMI, and it is 34 . Vital signs are unremarkable. Heart sounds show regular rate and rhythm, and lungs are clear to auscultation bilaterally. Her abdomen is gravid, and her fundus is

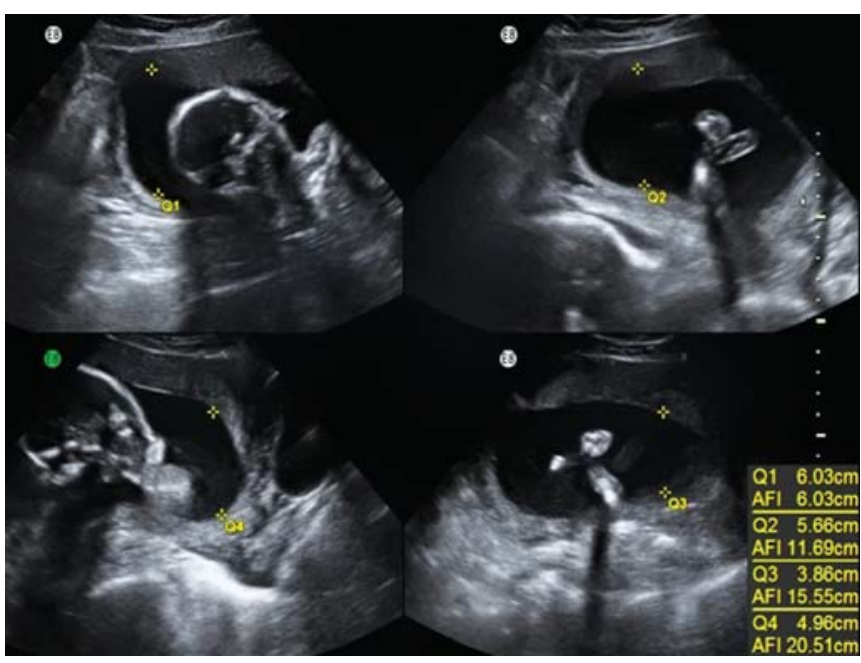

Fig. 2: Demonstration of amniotic fluid assessment

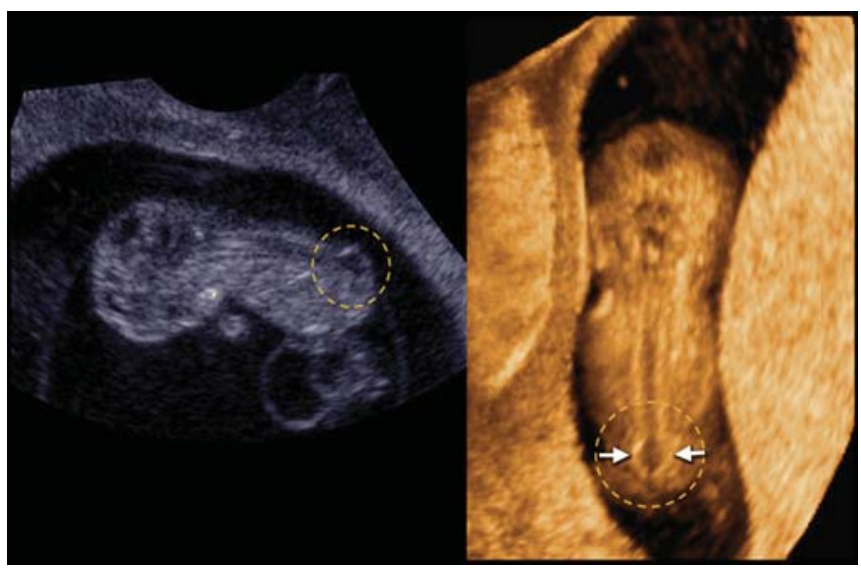

Fig. 3: Transvaginal 2D (left) and 3D (right) image of the fetal spine at 9 weeks of gestation. Courtesy. Pooh R, MD

pal pable. Y ou perform an ultrasound (Fig. 3). Y ou estimate the fetus to be approximately 9 weeks gestation.

\section{Case 4}

A 34-year-old G3P2012 woman presents for her routine prenatal care appointment at 32 and 3/7 weeks' gestation. She has a history of type 1 diabetes. She denies any headache, nausea, vision changes or edema. She has continued to take her prenatal vitamins and works to maintain a healthy diet and minimal exercise routine. She has had two previous pregnancies, with two-term vaginal deliveries. On physical exam, the patient is a gravid obese female. Fetal heart tones by Doppler are variable, with baseline of approximately 145 beats per minute (bpm). Fundal height: $36 \mathrm{~cm}$ (up $6 \mathrm{~cm}$ since her appointment 4 weeks ago). The patient is sent for sonogram. The sonographer sees something that is concerning, and progresses to perform fetal echocardiography and take Doppler views of the fetal heart (Figs 4 and 5). 


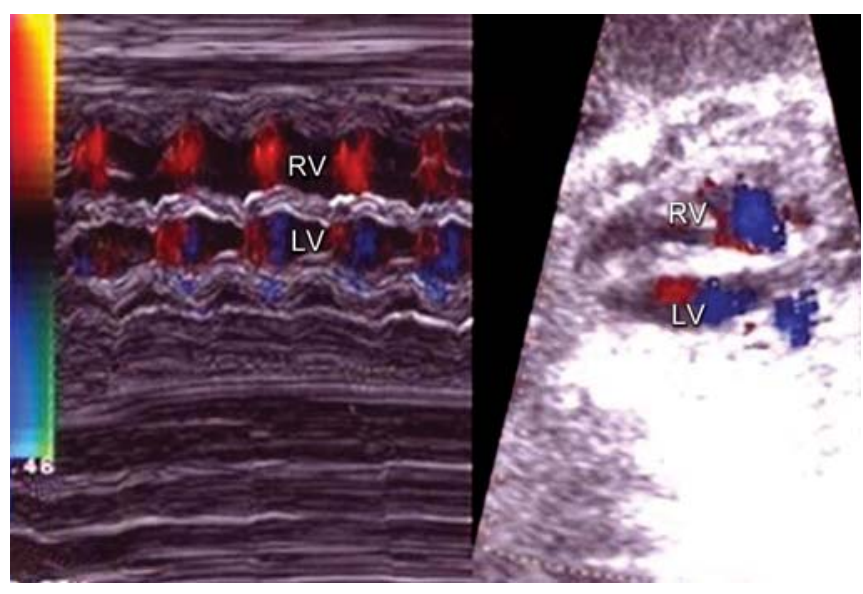

Fig. 4: Color Doppler image of the normal fetal heart, measuring the thickness of the interventricular septum by M-mode, in a 4-chamber view from a normal heart. RV: right ventricle; LV: left ventricle. Courtesy: Carmina Comas Gabriel, MD

\section{Case 5}

A 47-year-old G 3P3003 patient presents at the clinic with the complaint of irregular periods. For the past year her periods have been heavier than usual lasting 5 to 14 days and have come at irregular intervals. Her last menstrual period was about 1.5 months ago, but she is unsure of the exact date it started. The patient believes that she is undergoing menopause and would like to 'see about doing something to hurry it along'. She denies ever experiencing hot flashes, night sweats, emotional ups and downs, confusion, and dyspareunia. Past medical history is significant for type $2 \mathrm{DM}$ that was diagnosed 15 years ago and is controlled with metformin and insulin. Her blood sugars are reportedly well controlled, according to the patient. She has had three term deliveries all by cesarean section. On pelvic exam the uterus is mildly enlarged. Leiomyoma are suspected and the patient is sent for laboratory work and transvaginal ultrasound. Ultrasound

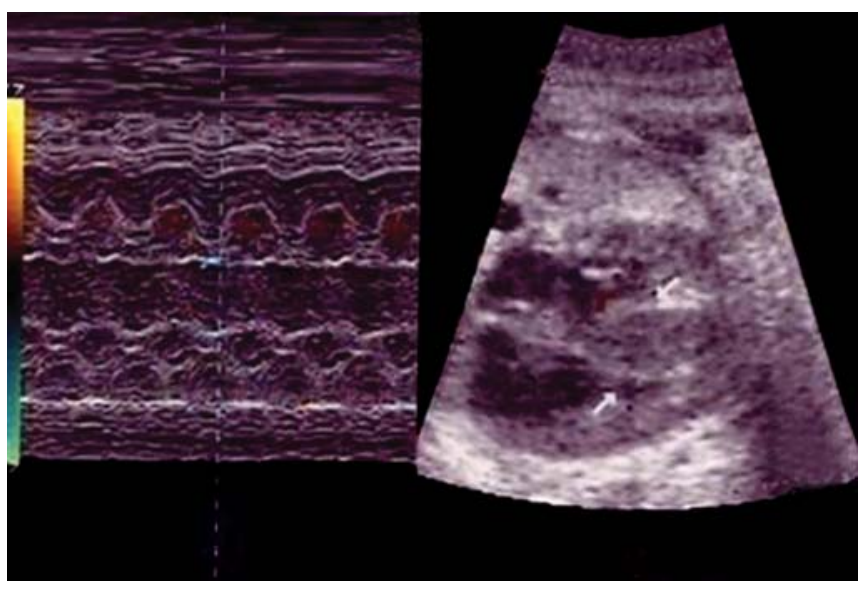

Fig. 5: Color Doppler image of the fetus from Case 4. Note the difference in the thickness of the interventricular septum and compare it with the findings in Figure 4. Courtesy: Carmina Comas Gabriel, MD

results indicate intrauterine pregnancy of approximately 6 weeks gestation (Fig. 6).

\section{Case 6}

A 42-year-old A frican-A merican G 4P2012 type 2 diabetic patient at 15 weeks by last menstrual period arrives at your prenatal clinic in a panic, with complaints of vaginal bleeding for 2 days. The patient is especially distressed as she tells you 'it's happening again!' W hen you ask her what she means, she explains that she had a previous miscarriage with her last pregnancy at age 38, at 14 weeks.

The patient established care at your clinic at approximately 6 weeks gestation. At this time, she informed you that she was not planning this pregnancy with her husband. She was concerned, because she had been diagnosed with type 2 DM only 1 year before. Since her diagnosis, she has tried to control her diabetes by diet and exercise alone, but admits that she has found difficulty in making these lifestyle
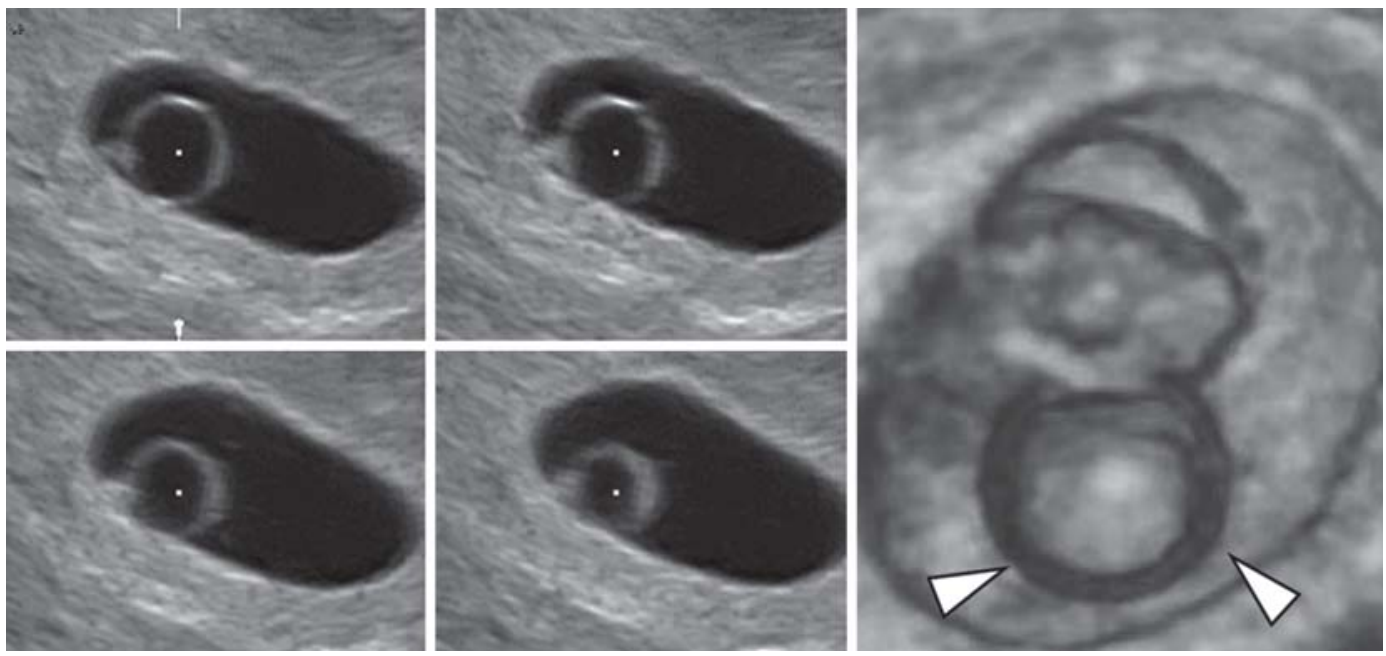

Fig. 6: Transvaginal ultrasound and 3D image of yolk sac in a diabetic patient. Courtesy. Pooh R, MD 


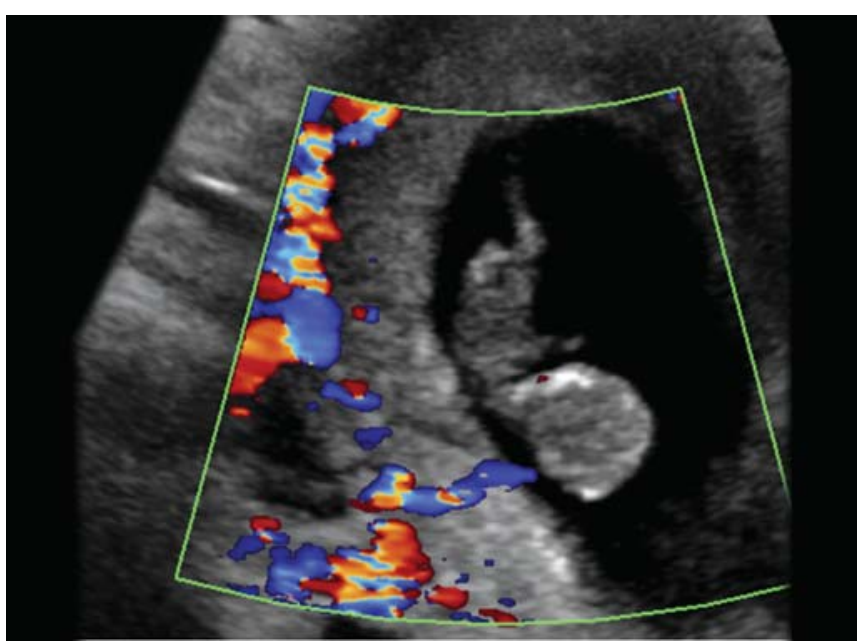

Fig. 7: Color Doppler sonogram-Case 6

changes. A this time, you performed an $\mathrm{HbA} 1 \mathrm{C}$, and found it to be $8.0 \%$. Her B M I was measured at 32. Y our patient's medical history is unremarkable except for the type $2 \mathrm{DM}$. $\mathrm{Her}$ other two pregnancies were unremarkable, normal spontaneous deliveries at ages 22 and 30 . Her social history is unremarkable. U pon speculum examination, cervical os is closed. There is pooling of liquid in the vaginal canal. Y ou perform an ultrasound (Figs 7 to 9).

\section{Case 7}

A 30-year-old G3P2002 African-A merican female at approximately 27 weeks gestation presents for her second prenatal visit at your clinic. During her first prenatal visit, she told you she had a history of type $2 \mathrm{DM}$ and hypertension for 3 years. Y ou discussed with her proper diet and lifestyle changes. Today, she reports that she has not been able to implement these changes due to financial struggles. The patient does not want to take any medications for her comorbidities, also due to the financial burden. During her first prenatal visit, she also disclosed that she had been using cocaine for 2 years prior to pregnancy. She has tried to stop, but is finding it difficult, and thinks she is addicted. Y ou have provided a name and number for a local counseling center to help her beat her addiction. $Y$ ou perform an ultrasound on your patient to determine dating and fetal biometry, as seen in Figures 10 to 12 .

\section{DISCUSSION}

As obesity and type 2 DM continue to be an ever growing problem in the United States, so does the public health concern of gestational diabetes and its effects on pregnancy. ${ }^{10}$ In recent years the prevalence of gestational diabetes has been increasing in countries across the world. It is common in various ethnic populations. The rates of

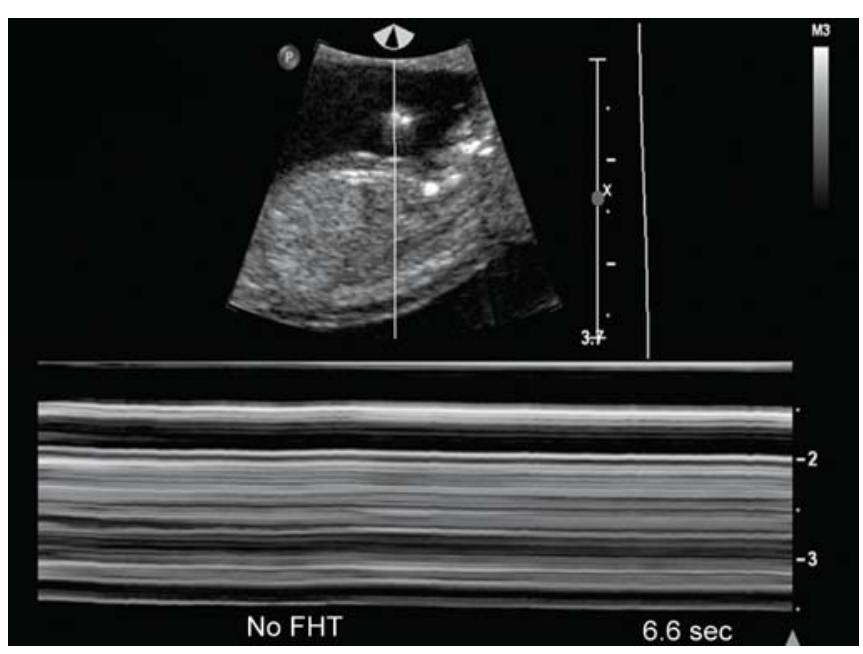

Fig. 8: M-mode ultrasound-Case 6

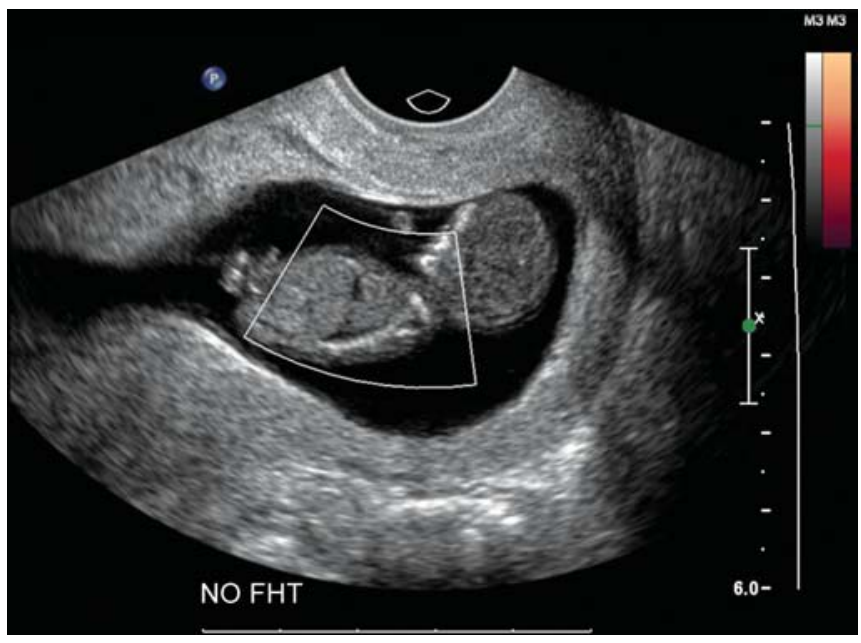

Fig. 9: Power Doppler sonogram-Case 6

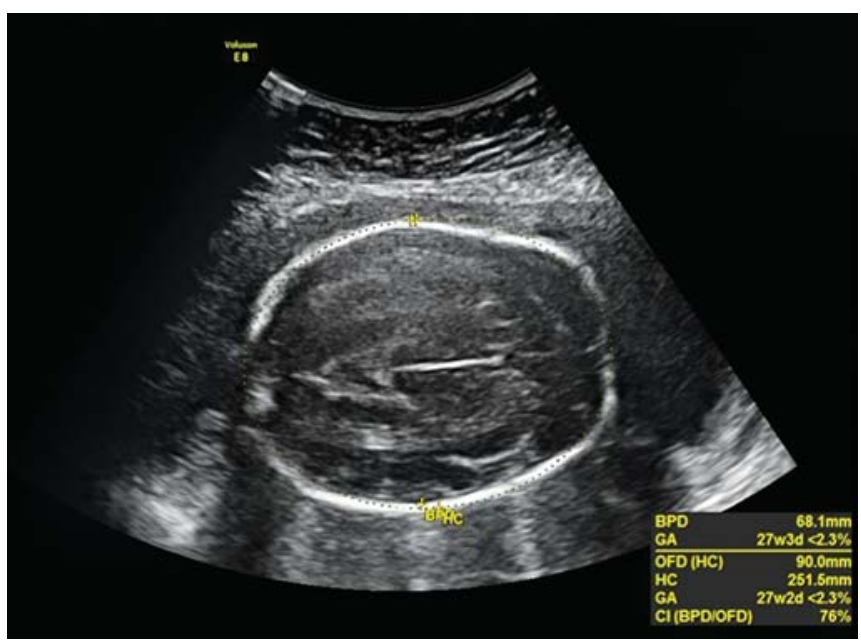

Fig. 10: Biparietal diameter (BPD) corresponding to 27 weeks 3 days

gestational diabetes are highest in Hispanic and African A merican women. ${ }^{11}$ Gestational diabetes also affects mothers of many different ages. In $2007,8.7 \%$ of the 


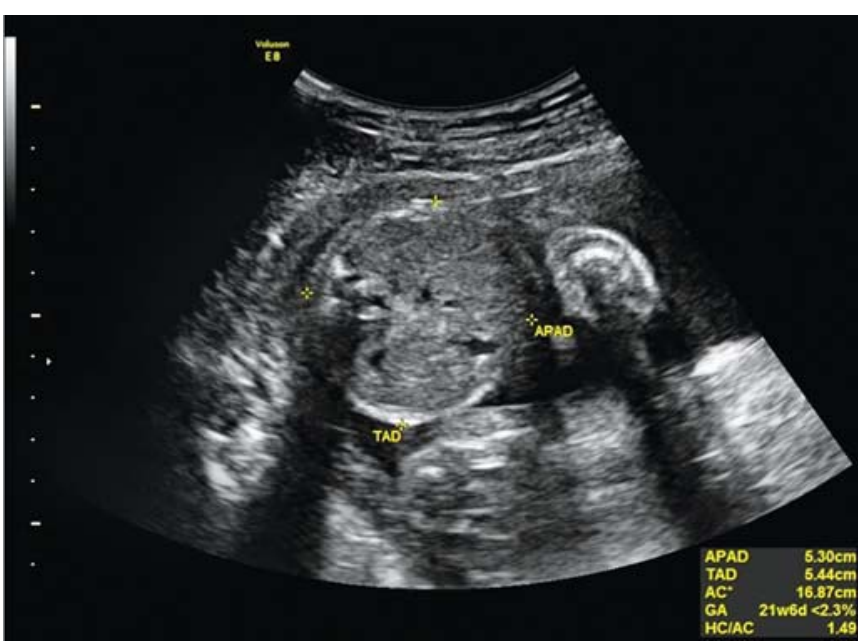

Fig. 11: Abdominal circumference (AC) corresponding to 21 weeks 6 days

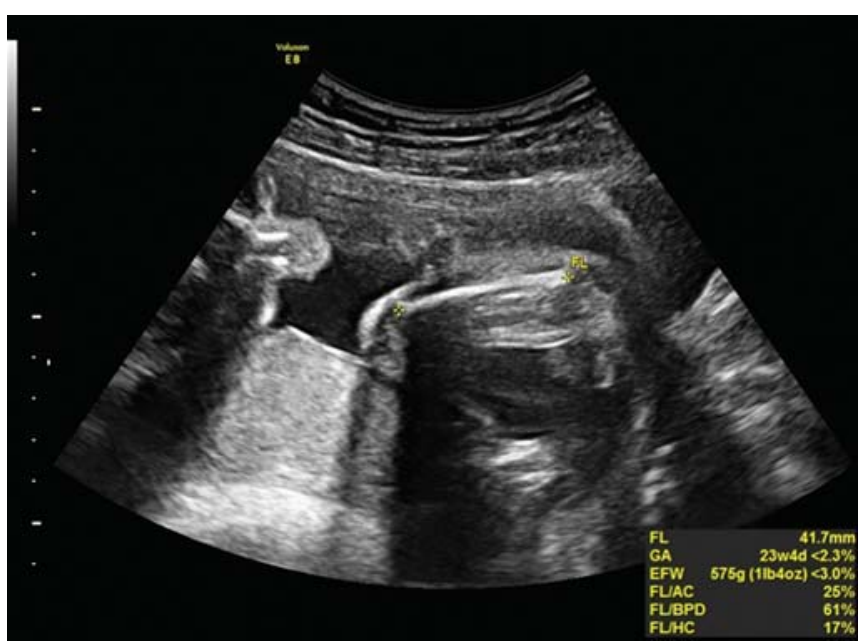

Fig. 12: Femur length (FL) corresponding to 23 weeks 4 days

Table 1: Comparison of American Diabetes Association (ADA) and American College of Obstetrics and Gynecology (ACOG) guidelines on GDM screening

\begin{tabular}{lll}
\hline Screening type & $\begin{array}{l}\text { American Diabetes Association } \\
\text { (ADA) guidelines }\end{array}$ & $\begin{array}{l}\text { American College of Obstetrics and Gynecology } \\
\text { (ACOG) guidelines }\end{array}$
\end{tabular}

Screening for GDM All women not previously diagnosed with diabetes should have a screening test performed at 24 to 28 weeks gestation using a 75 g OGTT, with plasma glucose measurement fasting, at 1 and 2 hours. Pretest fasting should be overnight and at least 8 hours in duration.

GDM is diagnosed when any of the following plasma glucose values are met or exceeded: ${ }^{13}$

- Fasting $\geq 92 \mathrm{mg} / \mathrm{dL}(5.1 \mathrm{mmol} / \mathrm{L})$

- $1 \mathrm{~h} \geq 180 \mathrm{mg} / \mathrm{dL}(10.0 \mathrm{mmol} / \mathrm{L})$

- $2 \mathrm{~h}>153 \mathrm{mg} / \mathrm{dL}(8.5 \mathrm{mmol} / \mathrm{L})$

Only one abnormal value is required for diagnosis, thus increased incidence of GDM is expected. ADA finds the increased incidence acceptable as the majority of women diagnosed with mild GDM can be effectively treated with only lifestyle modification.

Screening for underlying, prepregnancy DM

Testing for persistent $\mathrm{DM}$
All women who have risk factors for type 2 DM should be screened for prepregnancy DM type 2 at the first prenatal visit using the standard (non-GDM) diagnostic criteria for diabetes mellitus. Positive test results at this visit carry the diagnosis of DM, not GDM

At 6 to 12 weeks' postpartum, all women with GDM should be tested for persistent DM using a test other than hemoglobin A $1 C$ and nonpregnant testing criteria. Women with a history of GDM should be continually screened every 3 years for the development of DM. Women with a history of GDM found to have prediabetes should receive interventions including lifestyle modifications and drug therapies
ACOG continues to recommend use of prior GDM diagnostic criteria which includes the following:

- All pregnant women should be screened for GDM by one of the following: patient history, clinical risk factors, or a $50 \mathrm{~g}, 1$ hour OGTT

- GDM diagnosis should be made based on the results of a $100 \mathrm{~g}, 3$ hours OGTT

GDM is diagnosed with the $100 \mathrm{~g}, 3$ hour OGTT using either the plasma or serum glucose level. Diagnosis is made when any two or more of the following values are met or exceeded:

Plasma or Serum Glucose Level (Carpenter and Custan Conversion): $:^{14}$

- Fasting $\geq 95 \mathrm{mg} / \mathrm{dL}(5.3 \mathrm{mmol} / \mathrm{L})$

- $1 \mathrm{~h} \geq 180 \mathrm{mg} / \mathrm{dL}(10.0 \mathrm{mmol} / \mathrm{L})$

- $2 \mathrm{~h}>155 \mathrm{mg} / \mathrm{dL}(8.6 \mathrm{mmol} / \mathrm{L})$

- $3 \mathrm{~h} \geq 140 \mathrm{mg} / \mathrm{dL}(7.8 \mathrm{mmol} / \mathrm{L})$

Plasma Level (National Diabetes Data group Conversion): ${ }^{14}$

- Fasting $>105 \mathrm{mg} / \mathrm{dL}(5.8 \mathrm{mmol} / \mathrm{L})$

- $1 \mathrm{~h} \geq 190 \mathrm{mg} / \mathrm{dL}(10.6 \mathrm{mmol} / \mathrm{L})$

- $2 \mathrm{~h} \geq 165 \mathrm{mg} / \mathrm{dL}(9.2 \mathrm{mmol} / \mathrm{L})$

- $3 \mathrm{~h} \geq 145 \mathrm{mg} / \mathrm{dL}(8.0 \mathrm{mmol} / \mathrm{L})$

$P$ reconceptional analysis recommendations:

- Evaluation of underlying vasculopathy

- 24-hour urine collection for protein excretion and creatinine clearance

- ECG

- Daily multivitamin regimen

At 6 to 12 weeks' postpartum, all women with GDM should be screened for persistent $D M$, using either fasting plasma glucose (FPG) level or a $75 \mathrm{~g}$ 2 hours OGTT.

Positive results on both tests include an FPG of $\geq 126 \mathrm{mg} / \mathrm{dL}$. Any 2 hours glucose value of $\geq 200$ is also positive for diagnosis of DM. If a patient tests negative, her glycemic status should be rechecked every 3 years. 
The Role of Ultrasound in the Diagnosis of Complications Associated with Maternal Diabetes

gestational diabetic population was over the age of $36.4 .7 \%$ of this population were ages 26 to $30 .{ }^{11}$ The World Health Organization has identified this as a global health concern related to multiple risk factors. ${ }^{12}$ This is a concerning fact as elevated blood sugars in pregnancy can be detrimental to a fetal development, in some cases even fatal. A s such, it is important to utilize multiple screening modalities in order to identify these complications in utero. Organizations such as A merican Congress of Obstetrics and Gynecology (ACOG) and A merican Diabetes A ssociation have come up with guidelines for diagnosis of diabetes in pregnancy (Table 1). ${ }^{13,14}$

Ultrasound is a noninvasive screening method which physicians may use to identify physical abnormalities in utero with good accuracy. ${ }^{15}$ Early identification of these abnormalities allows for decisions to be made regarding continuing gestation and mentally preparing patients about the health of their baby in the future. ${ }^{15}$

\section{Fetal Acrania}

In case 1, a 28-year-old G 1P0 with history of heightened pregestational sugars had significant findings on her ultrasound as seen in Figure 1. The 11-week fetus had intact facial bones. However, there was no fetal skull. This fetus was diagnosed with fetal acrania. Fetal acrania is a devastating cranial malformation that is incompatible with life. Early diagnosis of fetal acrania can typically occur around 12 weeks gestation. ${ }^{16}$ There has also been a study suggesting measurement of crown-chin length as a potential diagnostic tool, as fetuses with acrania have shortened crown-chin lengths. ${ }^{17}$

Early diagnosis is important as termination of the pregnancy is typically recommended upon finding the defect. In these cases, the fetus will develop central nervous tissue but will not form a complete cranium. The fetus may form a partial cranium with protrusion of the nervous tissue through the defect or no cranium at all. Early diagnosis can be made in the first trimester via 2D or 3D ultrasound between 11 and 14 weeks gestation. M any cases report having diagnosed fetal acrania during a routine examination of nuchal translucency. The ultrasound will show the presence of facial bones and orbits, with partial or complete absence of the calvarium. The brain may be fully developed but amorphous and surrounded by amniotic fluid. ${ }^{18-21}$

\section{Polyhydramnios}

$N$ ot all complications of gestational diabetes are quite as destructive as fetal acrania. In case 2, the levels of amniotic fluid were measured to be larger than expected. This pregnancy was complicated by polyhydramnios. Poly- hydramnios is a condition in which there is more amniotic fluid volume than expected relative to gestational age. There are several known causes of polyhydramnios, such as gestational diabetes, developmental gastrointestinal abnormalities and iatrogenic causes. A primary risk factor for polyhydramnios is uncontrolled blood sugar. It is believed to affect between 1 and 3\% of all pregnancies. The detriment to the devel oping embryo is debatable. Some studies have indicated perinatal mortality to be between 10 and $30 \%,{ }^{22}$ while others have shown little to no evidence of perinatal morbidity and mortality. It is further shown that well controlled blood sugar in pregnancy decreases the chances of harm to the fetus related to the increase in amniotic fluid. It is generally agreed upon that polyhydramnios does increase the chance of preterm birth rates. ${ }^{22-24}$ The prognosis of polyhydramnios is related to the etiology. Ultrasound can be used to assess the volume of amniotic fluid by measuring the depth of the maximum vertical pocket. This is defined as the deepest pocket of amniotic fluid in the anteroposterior plane of the uterus which contains zero fetal parts. N ormal depth is considered to be between 2 and $8 \mathrm{~cm}$, with anything greater than $8 \mathrm{~cm}$ being considered polyhydramnios. This measuring technique was made more accurate with the adaptation of the amniotic fluid index (A FI). The uterus is divided into 4 quadrants and the depth of the maximum vertical pocket is found in each quadrant. The sum of these depths is the A FI. A normal index is between 8 and $18 \mathrm{~cm}$. A ny index greater than $21 \mathrm{~cm}$ is diagnostic for polyhydramnios. ${ }^{25}$

\section{Spina Bifida}

The ultrasound in case 3 shows spina bifida. Spina bifida is caused by failed closure of the caudal portion of the neural tube by 28 days gestation. N eural tube defects are most often associated with folic acid deficiencies in early gestation but studies have shown that obesity and gestational diabetes also contribute to these defects. Gestational diabetes and severe obesity are known risk factors for spina bifida and other neural tube defects. ${ }^{26,27}$ One study saw that among mothers of babies with spina bifida, many were Caucasian and Hispanic. $^{27}$

In general terms, there are two types of spina bifida, open and closed. Open lesions are more severe and refer to protrusion of the spinal cord through the defective vertebrae. These can cause motor deficits. Closed lesions do not protrude through the spinal column defect, and are considered less severe. Closed neural tube defect may only manifest as a tuft of hair on the skin overlying the defect. Severe neural tube defects can easily be identified in the first trimester using transvaginal ultrasound. The defect 
looks like a thin-walled cystic mass. Severe neural tube defects may also show the lemon and banana sign when assessing fetal cranium using ultrasonography in the second trimester. The 'banana sign' is a finding on ultrasound in which the cerebellum has an abnormal configuration and looks like a banana. The 'lemon sign' refers to the flattening of the frontal bones of the skull making it have the appearance of a lemon on cross section. B oth of these signs may be found with ultrasound but they are not specific to spina bifida. Closed neural tube defects may not be visible via ultrasound prior to the second trimester. ${ }^{28,29}$

\section{Hypertrophic Cardiomyopathy}

Other very serious complications associated with maternal diabetes are cardiovascular malformation and cardiomyopathy. The color D oppler of case 4 showed a thickened interventricular septum in the fetal heart, which is typical of hypertrophic cardiomyopathy. There is a significant amount of evidence that indicates a direct link between maternal diabetes and cardiovascular malformations. This is of the utmost clinical importance because if interventions are taken early to maintain glycemic levels these cardiovascular defects may be avoided. Early identification of any heart defect is very important so that the parents may be advised to contact a cardiology specialist. ${ }^{30,31}$ Ultrasonography is the diagnostic method of choice in finding prenatal hypertrophic cardiomyopathy. The primary finding is a significantly thickened interventricular septum discovered around 32 weeks gestation. ${ }^{32,33}$

A study has shown that women with type 1 or 2 DM have a higher risk of pregnancy complicated by cardiac hypertrophy than patients with gestational diabetes. ${ }^{34}$

\section{Increased Yolk Sac Diameter}

The sonogram in case 5 showed a yolk sac that was increased in size. In recent years, there have been studies that found an increase in the size of the yolk sack relative to gestational age. One study in particular, using $2 \mathrm{D}$ and $3 \mathrm{D}$ ultrasound in the first trimester, showed a particular increase in yolk sac diameter in pregnancies complicated by diabetes. ${ }^{35} \mathrm{This}$ observation has the potential to be very important in diagnosing gestational diabetes prior to symptom onset. It is theorized that the increase in yolk sack size may be an early sign of gestational diabetes. Identifying gestational diabetes prior to the onset of symptoms would allow practitioners to introduce an early treatment in order to minimize developmental abnormalities. ${ }^{36}$

\section{Missed Abortion}

In case 6, color and power Doppler ultrasound revealed spiral artery and intervillous blood flow, but the absence of fetal heartaction (Figs 7 to 9). This is diagnostic of a missed abortion. By far one of the most concerning complications of pregestational maternal diabetes is spontaneous abortion. Studies have shown that patients with higher, uncontrolled blood sugar, as well as mothers of increased maternal age have increased risk for spontaneous abortion within the first trimester. ${ }^{37}$ Pre-existing diabetes mellitus is al so a risk factor for miscarriage. ${ }^{38}$ Increased risk of spontaneous abortion has been associated with hemoglobin A1C of $6.7 \%$ and higher. This is another reason why early diagnosis and control of elevated blood sugars is so important. Patients may present with abnormal uterine bleeding, a history of previous spontaneous abortion, and long standing uncontrolled diabetes. Ultrasound may show the retained fetus with an absent heartbeat. With Doppler studies spiral artery and intervillous blood flow may be appreciated in the absence of fetal heart action. The retained products of conception may require removal. ${ }^{37}$

\section{Intrauterine Growth Restriction}

In case 7 , the gestational age was estimated differently when measured by various anatomical landmarks. This is diagnostic of IUGR or intrauterine growth restriction. In the past decade, pregnancy at later maternal age has become more prevalent and this has led to studies about the associations between advanced maternal age and IUGR. $M$ any studies have show $n$ other risk factors IU GR including maternal diabetes, African-A merican race, chronic hypertension, and cocaine use during early pregnancy. ${ }^{39}$ IUGR can be most simply defined as a birth weight in the lower 10\% for a given gestational age. Intrauterine growth can be assessed by ultrasound based on the measurements of biparietal diameter (BPD), head circumference $(H C)$, abdominal circumference $(A C)$ and femur length $(F L)$ between 32 and 34 weeks for patients at high risk. Serial ultrasounds at 4 week intervals through the second and third trimesters lowers the false positive rate and may also be used for diagnosis. ${ }^{40}$ IU GR is associated with intrauterine death and it is important to identify it as early as possible. The best approach to minimizing IUGR and its complications is adequate prenatal care. Prevention of IU GR may be achieved through smoking cessation, pregestational control of chronic conditions such as diabetes and hypertension, and initiating low dose aspirin early in pregnancy. ${ }^{41-43}$ 
The Role of Ultrasound in the Diagnosis of Complications Associated with Maternal Diabetes

\section{REFERENCES}

1. Nicholson W, B olen S, W itkop C, Neale D, W ilson L, B ass E. $B$ enefits and risks of oral diabetes agents compared with insulin in women with gestational diabetes: a systematic review. Obstet Gynecol 2009 J an;113(1):193-205.

2. Kim SY, England L, W ilson HG, Bish C, Satten GA, Dietz P. Percentage of gestational diabetes mellitus attributable to overweigh and obesity. A m J Public Health 2010 Jun; 100(6):1047-1052.

3. Sanada H, Y okokawa H, Y oneda M, Y atabe J, Sasaki Y atabe $M$, W illiams SM, Felder RA, J ose PA. High body mass index is an important risk factor for the development of type 2 diabetes. Intern M ed 2012;51(14): 1821-1826.

4. Hunt KJ, Schuller K L. The increasing prevelance of diabetes in pregnancy. O bstet Gynecol Clin North A m 2007 J un;34(2):173199.

5. Gardosi J, M adurasinghe V, W illiams M, M alik A, Francis A. $M$ aternal and fetal risk factors for stillbirth: population based study. B M J 2013 Jan;346:108.

6. Rosenberg TJ, Garbers S, Lipkind H, Chiasson M A. M aternal obesity and diabetes as risk factors for adverse pregnancy outcomes: differences among $4 \mathrm{racial} /$ ethnic groups. A mJ Public Health 2005 Sep;95(9):1545-1551.

7. Committee Opinion No. 504: screening and diagnosis of gestational diabetes mellitus. Obstet Gynecol 2011 Sep; 118(3):751-753.

8. Wahabi HA, Alzeidan RA, Esmaeil SA. Pre-pregnancy care for women with pre-gestational diabetes mellitus: a systematic review and meta-analysis. BM C Public Health 2012 Sep; 12:792.

9. Crowther CA, Hiller JE, M oss JR, M CPhee AJ, J effries WS, Robinson JS. Effect of treatment of gestational diabetes mellitus on pregnancy outcomes. N Engl J M ed 2005 J un;352(24):24772486.

10. Getahun D, Nath C, A nanth CV, Chavez M R, Smulian JC. Gestational diabetes in the United States: temporal trends 1989 through 2004. A m J Obstet Gynecol 2008 M ay;198(5):525. el-5.

11. Chen Y, Quick W, Y ang W, Zhang Y, Baldwin A, M oran J, M ooreV, Sahai N, Dall TM . Cost of gestational diabetes mellitus in the United States in 2007. Popul Health M anag 2009 J un;12(3):165-174.

12. Doyle MA, K han S, AI-M ohandi D, K eely E. International survey on gestational diabetes. J M atern Fetal M ed 2012 Oct;25(10):2035-2038.

13. A merican Diabetes Association. Standards of medical care in diabetes-2012 (Position Statement). Diabetes Care 2012;35 (Suppl 1):S11-S63.

14. A COG Committee Opinion N 0. 435: Postpartum screening for abnormal glucose tolerance in women who had gestational diabetes mellitus. Obstet Gynecol 2009 J un;113(6):1419-1421.

15. Correa A, Gilboa SM, B esser LM , B otto LD, M oore CA, Hobbs CA, Cleves M A, Riehle-Colarusso TJ, Waller K, Reece A. Diabetes mellitus and birth defects. A m J O bstet Gynecol 2008 Sep;199(3):237.e1-9.

16. Johnson SP, Sebire NJ, Snijders RJ, Tunkel S, Nicolaides K H. Ultrasound screening for anencephaly at 10-14 weeks of gestation. U Itrasound Obstet Gynecol 1997 Jan;9(1):14-16.

17. Sepulveda W, Sebire NJ, Fung TY, Pipi E, Nicolaides KH. Crown-chin length in normal and anencephalic fetuses at 10 to 14 weeks' gestation. A m J Obstet Gynecol 1997 A pr;176(4): 852-855.
18. Hawkins JS, Case BM. Labor and delivery management for women with diabetes. Obstet Gynecol Clin North A m 2007 J un;34(2):323-334.

19. A min MU, M ahmood R, N afees $M$, Shakoor T. Fetal acraniaprenatal sonographic diagnosis and imaging features of aborted fetal brain. J Radiol Case Rep 2009;3(7):27-34.

20. Cheng CC, Lee FK, Lin HW, Shih JC, Tsai M S. Diagnosis of fetal acrania during the first trimester nuchal translucency screening for Down syndrome. Int J Gynaecol Obstet 2003 Feb;80(2):139-144.

21. Liu IF, Chang $\mathrm{CH}, \mathrm{Y}$ u CH, Cheng Y C, Chang FM. Prenatal diagnosis of fetal acrania using three-dimensional ultrasound. Ultrasound M ed Biol 2005 Feb;31(2):175-178.

22. V olante $E$, Gramellini D, M oretti S, K ai hura C, B evilacqua G. Alteration of the amniotic fluid and neonatal outcome. Acta Biomed 2004;75 Suppl 1:71-75.

23. Shoham I, W iznitzer A, Silberstein T, Fraser D, H olcberg G, Katz M, M azor M. Gestational diabetes complicated by hydramnios was not associated with increased risk of perinatal morbidity and mortality. Eur J Obstet Gynecol Reprod Biol 2001 Dec;100(1):46-49.

24. Idris N, Wong SF, Thomae M, Gardener G, M cintyre DH. Influence of polyhydramnios on perinatal outcome in pregestational diabetic pregnancies. Ultrasound Obstet G ynecol 2010 Sep;36(3):338-343.

25. Marino T. Ultrasound abnormalities of the amniotic fluid, membranes, umbilical cord, and placenta. O bstet Gynecol Clin North A m 2004 M ar;31(1):177-200.

26. Rasmussen SA, Chu SY, K im SY, Schmid CH, Lau J. M aternal obesity and risk of neural tube defects: a meta-analysis. A m J Obstet Gynecol 2008 J un;198(6):611-619.

27. A nderson JL, W aller DK, Canfield M A, Shaw GM, Watkins $M L$, Werler M M. M aternal obesity, gestational diabetes, and central nervous system birth defects. Epidemiology 2005 Jan;16(1):87-92.

28. Benacerraf BR, Stryker J, Frigoletto FD. A bnormal US appearance of the cerebellum (banana sign): indirect sign of spina bifida. Radiology 1989 A pr;171(1):151-153.

29. Ghi T, Pilu G, Falco P, Segata M, Carletti A, Cocchi G, Santini $D$, Bonasoni P, Tani G. Prenatal diagnosis of open and closed spina bifida. Ultrasound Obstet Gynecol 2006 Dec;28(7): 899-903.

30. Loffredo CA, Wilson PD, Ferencz C. M aternal diabetes: an independent risk factor for major cardiovascular malformations with increased mortality of affected infants. Teratology 2001 A ug;64(2):98-106.

31. W ren $\mathrm{C}$. Cardiovascular malformations in infants of diabetic mothers. Heart 20030 ct;89(10):1217-1220.

32. Zielinsky P. R ole of prenatal echocardiography in the study of hypertrophic cardiomyopathy in the fetus. Echocardiography $1991 \mathrm{~N} \mathrm{ov} ; 8(6): 661-668$.

33. V eille JC, Sivakoff M, Hanson R, Fanaroff A A . Interventricular septal thickness in fetuses of diabetic mothers. Obstet $G$ ynecol 1992 Jan; 79(1):51-54.

34. Ullmo S, Vial Y, Di B ernardo S, Roth-K leiner M, M ivelaz Y, Sekarski N, Ruiz J, M eijboom EJ. Pathologic ventricular hypertrophy in the offspring of diabetic mothers: a retrospective study. Eur Heart J 2007 J un;28(11):1319-1325.

35. Cosmi E, Piazze J, Ruozi A, A nceschi MM, LaTorre R, Andrisani A, Litta P, Nardelli GB, A mbrosini G. Structuraltridimensional study of yolk sac in pregnancies complicated by diabetes. J. Perinat M ed 2005;33(2):132-136. 
36. Schoenfeld A, Erman A, Warchaizer S, Ovadia J, B onner G, Hodi M. Y olk sac concentration of prostaglandin E 2 in diabetic pregnancy: further clues to the etiology of diabetic embryopathy. Prostaglandins 1995;50(3):121-126.

37. Gutaj P, ZawiejskaA, W ender-o ¿egowska E, B r ${ }^{1}$ zert J . M aternal factors predictive of first trimester pregnancy loss in women with pregestational diabetes. Pol A rch M ed W ewn 2013;123(12):21-28.

38. Wahabi H, Esmaeil S, Fayed A, Al-Shaikh G, Alzeidan RA. Pre-existing diabetes mellitus and adverse pregnancy outcomes. B M C R esearch Notes 2012 Sep;5(496):1-5.

39. Odibo A O, N el son D, Stamilio D M, Sehdev HM, M acones GA. Advanced maternal age is an independent risk factor for intrauterine growth restriction. A m J Perinatol $2006 \mathrm{Jul}$; 23(5):325-328.
40. M ongelli M, Ek S, Tambyrajia R. Screening for fetal growth restriction: a mathematical model of the effect of time interval and ultrasound error. O bstet Gynecol 1998 D ec;92(6):908-912.

41. Frøen JF, Gardosi J O, Thurmann A, Francis A, Stray-Pedersen $B$. Restricted fetal growth in sudden intrauterine unexplained death. A cta O bstet Gynecol Scand 2004 Sep;83(9):801-807.

42. Bujold E, Roberge S, Lacasse $Y$, Bureau M, A udibert F, M arcoux S, Forest JC, Giguere. Prevention of pre-eclampsia and intrauterine growth restriction with aspirin started in early pregnancy: a meta-analysis. Obstet Gynecol 2010 A ug;116(2 Pt 1):402-414.

43. Grivell R, D odd J, Robinson J. The prevention and treatment of intrauterine growth restriction. Best Pract Res Clin Obstet Gynaecol 2009 Dec;23(6):795-807.

\section{SELF-ASSESSMENT QUIZ}

1. Early diagnosis of fetal acrania using 2D or 3D ultrasound is first possible during which of the following time frames?
a. 5-6 weeks' gestation
b. 6-7 weeks' gestation
c. 11-14 weeks' gestation
d. 14-17 weeks' gestation

2. A 36-year-old G 5P2022 woman presents for her first prenatal careappointment at 34 and 6/7 weeks' gestation. Shehas a history of uncontrolled diabetes mellitus type 2. On physical exam: gravid, obese female in no apparent distress. $F$ undal height: $40 \mathrm{~cm}$. Patient was immediately sent for an ultrasound due to clinical suspicion of increased amniotic fluid. Radiologist reports findings consistent with polyhydramnios and hypertrophic cardiomyopathy. Which of the following ultrasound findings is consistent with a diagnosis of hypertrophic cardiomyopathy in utero?
a. Bicuspid aortic valve
b. A ortic valve calcification with enlarged ventricles
c. Thickened interventricular septum with small fetal heart chambers
d. Coiled persisting ductus arteriosus with ventricular hypertrophy
e. Tricuspid mitral valve with regurgitation

3. Polyhydramnios is believed to affect between 1 and $3 \%$ of all pregnancies, with uncontrolled blood sugars being one of several causes. Polyhydramnios may be diagnosed by utilizing ultrasound to obtain the measurements needed for calculating the AFI. All of the following correctly describe the AFI except:

a. The gravid abdomen should be divided into four quadrants with measurements obtained in each quadrant. b. M easurements of the three deepest pockets are summed to give the final AFI.

c. A normal AFI is between 8 and $18 \mathrm{~cm}$, with an AFI greater than $21 \mathrm{~cm}$ diagnostic of polyhydramnios.

d. The depth of the maximum vertical pocket of amniotic fluid containing no fetal parts is found in each quadrant and a straight line, vertical measurement is taken of this deepest pocket.

4. Upon ultrasound, you discover that one of your patients is carrying a pregnancy with spina bifida. Which of the following is most important when counseling your patient about spina bifida?

a. Counseling them on possible therapies the baby might need

b. Counseling them on their options as far as terminating the pregnancy, or continuing with the pregnancy

c. Advising the mother that something she did during her pregnancy caused spina bifida

d. $a$ and $b$

e. $a$ and $c$

5. A 23-year-old obese G 2P1001 comes in for a first trimester ultrasound at 11 weeks. U pon measurement of the yolk sac, you notice it is enlarged. Which of the following conditions is most likely associated with this pregnancy?
a. Lupus nephritis
b. Hypoglycemia
c. Gestational diabetes
d. Pre-eclampsia

6. Upon ultrasound exam of a 30-year-old G 5P4004, you diagnose fetal acrania. Which of the following do you most likely see on ultrasound?
a. The 'banana' sign
b. A shortened crown-chin length 
c. Increased yolk sac diameter

d. A fetus that is measuring small for gestational age

7. Which of the following is the best prevention of IUGR?
a. A dequate prenatal care
b. Q uitting smoking
c. Control of hypertension and diabetes
d. All of the above

8. Which of the following is the correct finding on ultrasound of a missed abortion?
a. Empty gestational sac, close internal os
b. Open internal os, gestational products present with fetal heart action present
c. Presence of intervillous blood flow, but absent fetal heart action
d. Intervillous blood flow, fetus at approximately 22 weeks, with absent fetal heart action

9. According to ACOG, how is the diagnosis of GDM made?
a. By the fasting blood glucose
b. By the 3 hours GTT
c. By the increased yolk sac diameter on ultrasound
d. By the 1 hour GTT

10. Which of the following is not a potential risk for the pregnancy or future child of a mother with gestational diabetes?
a. Shoulder dystocia
b. Pre-eclampsia
c. Childhood obesity
d. Preterm delivery
e. All of the above are potential risks

\section{Answers}

1. c; 2. c; 3. b; 4. b; 5. c; 6. b; 7. d; 8. c; 9. b; 10.e

\section{ABOUT THE AUTHORS}

\section{Kallie Appleton}

Graduate of Paul L Foster School of Medicine, Department of Obstetrics and Gynecology, Texas Tech U niversity in EI Paso, Texas USA

\section{Jami Barnard}

Resident, Department of Obstetrics and Gynecology, Paul L Foster School of M edicine, Texas Tech U niversity in EI Paso, Texas, USA

\section{Adam K Jantz}

Student Physician, Department of Obstetrics and Gynecology, Texas Tech U niversity in EI Paso, Texas, USA

\section{Ritsuko Pooh}

Director, CRIFM Clinical R esearch Institute of F etal M edicine PM C Tennoji, Osaka, Japan

\section{Carmina Comas-Gabriel}

Director and C oordinator of Fetal M edicine Division, D epartment of Obstetrics, Gynecology and Reproductive M edicine, University Institute D exeus, B arcelona, Spain

\section{Sanja Kupesic-Plavsic}

Assistant A cademic Dean for Faculty Development, Professor of Obstetrics and Gynecology, Department of Obstetrics and Gynecology, Paul L Foster School of M edicine, Texas Tech U niversity in EI Paso, Texas, USA

Correspondence Address: 4800 A l berta A ve, EI Paso, Texas-79905 USA, Phone: +1(915)215 6505, e-mail: sanja.kupesic@ttuhsc.edu 


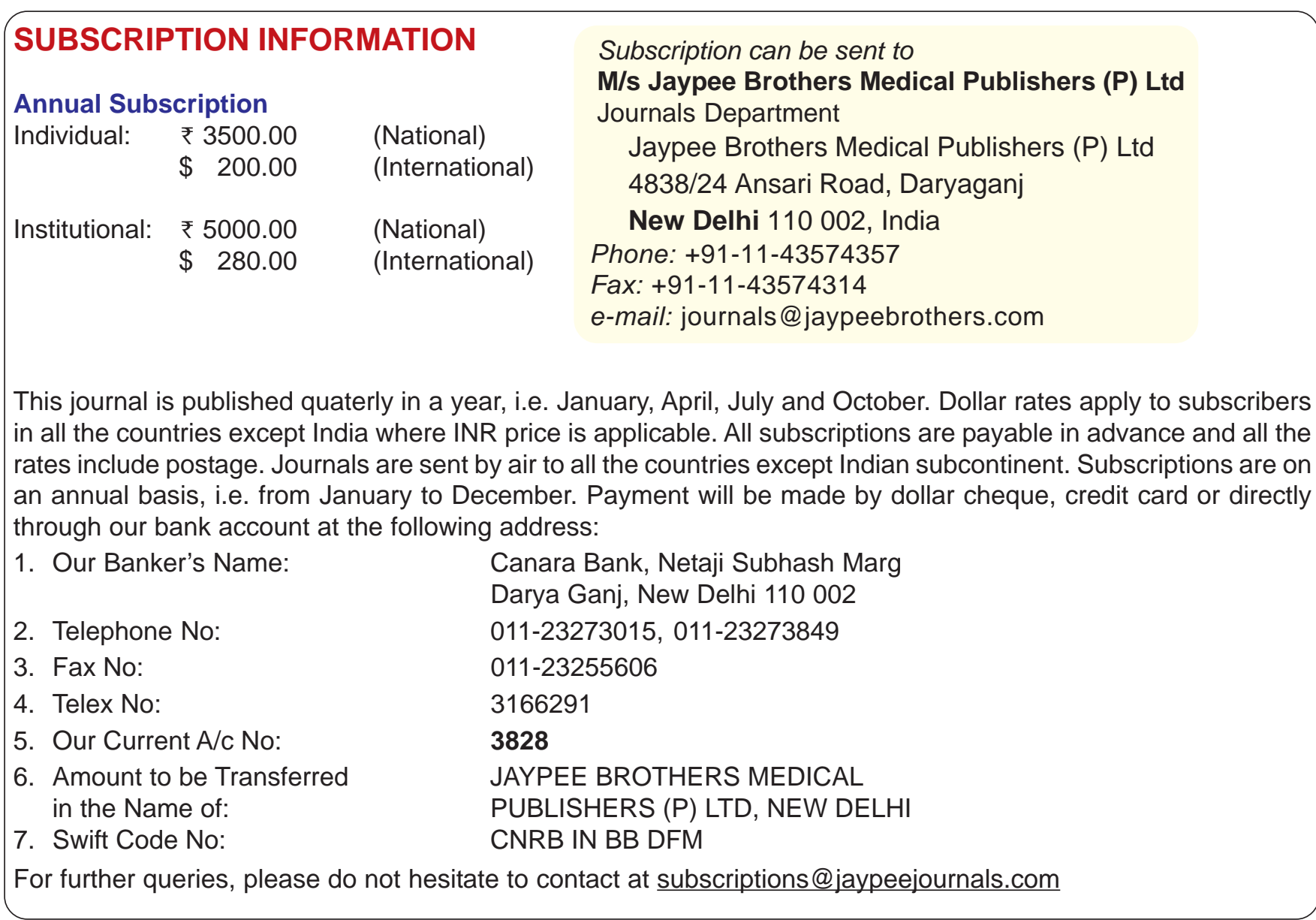

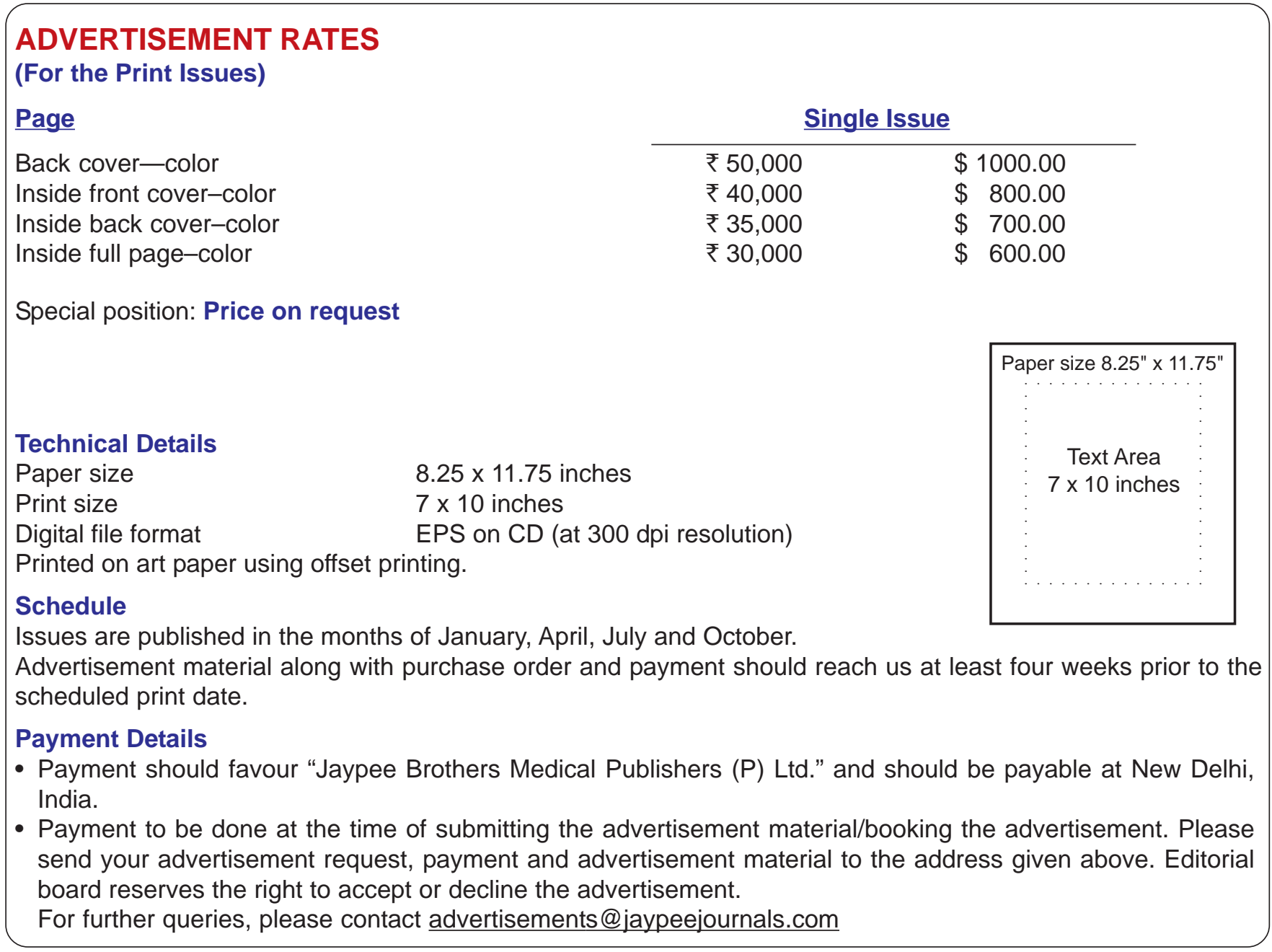

